\title{
O REGIME JURIDICO DAS TERRAS DA FAZENDA NACIONAL DE SANTA CRUZ
}

\author{
Luciano Pereira da SH.va
}

Consultor Jurídico do Minirtério da Agriculturn

SUMÁRIO : A Faxenda Nacional de Santa Crus. A Loi n. 601 , do 18-9-1850, e os Decretos de 25-11-1830 e n.0 1.318, de 30-1-1854. Decreto n.0 24.606, de 6-7-1934. Decreto-lei n.0 893, de 26-11-1938. Inversāo do ônus da prova. A Comissão Revisora de Títulos. Erame e legitimidade dos títulos. Benfeitorias. Preferência para aquisição. Cartas de arrematação. Vantagens do Decreto-lei n.* $^{\circ} 893$. Conclusões.

A Fazenda Nacional de Santa Cruz avulta entre os bens patrimoniais da União, assim por sua grande extensão como por ficar situada a pouca di.tância da cidade do Rio de Janeiro.

Antiga propriedade dos jesuítas, fôra-lhes confiscada pela coroa portuguêsa quando expulsos do reino e de suas colônias pelo Marquês de Pombal.

Formada por duas imensas sesmarias, uma de quatro lóguas de testada por quatro de ertensão e outra de seis léguas por outras seis, confinando e linha de fundos da primeira com a linha de frente da segunda, e apresentando uma área contínua de cinqüenta o duas léguas quadradas ou $1.872 \mathrm{k2}$, consti- 
tuia un latifúndic de gigantascas proporģōeg, mesmo para a tempo em quo foram dadas as sesmarias, posteríarmente deixadas em testamento pelos primitivos sesmeiros à Companinia de Jesus.

A Lei n. 601, de 18-9-1850, e os Decretos de 25-11-1830 e $n^{\circ} 1.318$, de

30-1-1854 - Revertendo ao patrimônio da Coroa, os reis de Portugal repartiram-nas em múltiplas peçuenss sesmarias, medindo geralmente urra légua quadrada, algumas delas meia légua quadrada e só por exceção áreas maiores. As sesmarias exam dadas sob várias condiçóes, inclusive a de seremn demarcadas dentro de determinado prazo, para que, confirmadas, passassein então para o domínio pleno dos sesmeiros. Como essa condição não fôsse satifeita por vários sesmeiros, mas continuassem as terras em poder dos sucessores dos mesmos, a Lei $\mathrm{n}^{\circ} 601$, de 18 de setembro de 1850 , regulamentada pelo Decreto n..$^{\circ} 1.318$, de 30 de jareiro de 1854 , mandou que se reconhecesse como legítima a propriedade de tás terras, desde que estivessem sendo aproveitadas e cultivades por seus atuais ocupantes.

Antes dessa grande lei, no reinado de D. Pedro I, baixara êste monarca - Decreto de 25 de novembro de 1830 , em cujo art. $1 .^{\circ}$ vinha descrita a então Imperial Fazenda de Santa Crux, já com a finalidade, não alcançada, entretarto, de extremar o que ainda era propriedade da Neção do que pa:sera a ser propriedade privadei $O_{s}$ conflitos entre as duas espécies de propriedada deveriam cessar, aplicando-se, para a respectiva discriminação, o critório estabelecido por aquela lei e seu regulamento, que era o que as condiçõ do país aconselharam fôsse adotado.

Estabilizou-se, por essa forma, a situeção, no momento, ficando as terrae que não foram consideradas alodiais submetidas a uri regime especial do eforamentos e arrendamentos, que se veio mantendo desde aquela época, . cargo de um órgäo - a Superintendência da Fazenda Nacional de Santa Cruz, autônomo na Monarquia e primeiros anos da República, mas subo:dinado, depois, a outro órgão de kierarquia superior, com jurisdição sôbre todos os bens patrimoniais dø Nação existentes em o território nacional - a Diretoria do Patrimônio Nacional, depois Diretoria do Domínio da Uniễo - atualmente Serviço do Patrimônio da União.

A Superintendência da Fazenda Nacional de Santa Cruz, pela sua finalidade específica, deveria possuir o cadastro de tôdas as terras que constituíam dita Fazendia, tal como está descrita no art. $10^{\circ}$ do Decreto de 25 de novembro de 1830 . Infelizmente, não sòmente falta aquêle cadastro geral coxna uma escrituração regular, pela qual se possa saber, com segurançe, o que

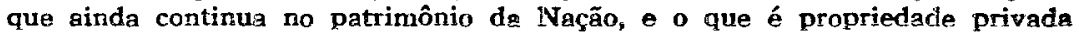
por título legítimo, quando se trata de terras ocupadas, matéria em que reirwa a maior confusão.

Resolvendo o Govêrno colonizar as terras do patrimônio nacional por meio de núcleos colonizis, incluiu nesse programa as de Śanta Cruz, mais próprias para êsse firn do que quaisquer outras. Poucos, porém, foram os resultados obtidos, porque a administração esbarrava sempre com ocupaçōes do particulares çue era preciso remover préviamente, sem que pudesse, entretanto distinguir os intrusos dos portadores de títulos legítimos, lançando mão, para isso, dos elementos existentes nos arquivos da Fazenda Nacional de Samta Crus.

Decreto n." 24.606, do 6-7-1934 - Vitoriosa a Revoluçäo de 1930 , vo perícdo que antecedeu a promulgação da Constituição de 1934, baixou o Govêrno Provisório o Decreto $\Omega^{\circ} 24.606$, de 6 de julho dêsse ano, no qual ermava a aưministraxão pública dos poderes extraordinários julgedos indi- 
pensáveis para pôr ordem na situaçāo quase caótica entāo reinante. Tendo sido, entretanto, aquêle decreto publicado já na vigência da Constituição, quando houve de ser pôsto em execução, surgiram entraves oriundos do excesso de arbitrio de quo investia o Govêrno, em face da legislação comum do país.

Decreto-lei n. 893 , de 26-11-1938 - Uma das medidas por êle provistas, o levantamento da planta cartográfica da Fazenda Nacional de Santa Cruz, chegou a ser executada pela Comissäo Fundadora do Núcleo Colonial Santa Cruz. Não puderam, entretanto, realizar-se as que tinham por objeto a discriminação das terras, continuando a situação de incertezas que devia resolver. Com o advento do Estado Nacional, o problema foi pôsto de novo em equação, entrando como têrmos da mesma os ensinamentos colhidos na execução do Decreto n.0 24.606, aparecendo como resultado o Decreto-lei n. ${ }^{\circ} 893$, de 26 de novembro de 1938, ainda com o caráter de lei especial, entremeada de disposiçōes que contrariam as da legislação comum, mas expungida do excesso de arbítrio que caræcterizava aquêle decreto do Govêrno Provisório.

Tem por ementa dispor - "Sôbre o aproveitamento agrícola da Fazenda Nacional de Santa Cruz e de outros imóveis da União", e em seu preâmbulo, com três consideranda, expōe os objetivos visados, que são:

a) a necessidade de incentivar o aproveitamento da dita Fazenda e de outros imóveis da União situados na Baixada Fluminense e beneficiados pelas obras de Saneamento que o Govêrno vem aí realizando;

b) pôr têrmo à ocupação indébita dessas terras, pertencentes à União por títulos inequívocos;

c) desenvolver a pequena propriedade nessa região, de que deveräo resultar vantagens consideráveis para o abastecimento da Capital da República e zonas adjacentes, visto não ter dado bom resultado o regime de arrendamentos e aforamentos aplicado às terras.

A chamada Baixada Fluminense, zona compreendida entre a costa oceânica e a Serra do Mar, apesar de sua proximidade da Capital da República, era uma verdadeira desolação, tal o abandono em que so mantinha. Infestada por endemias, em que sobressaem a malária e as verminoses, conservava-se despovoada e improdutiva, afugentando os que podiam aproveitar-lhe as terras, cuja desvalorização chegou 20 ponto de näo se importarem alguns de seus proprietários, com perdê-las nos executivos fiscais, para a cobrança de infimos impostos territoriais, que lhes eram movidos pela Fazenda Pública do Estado do Rio de Janeiro, depois de as abandonarem definitivamente, o que animou os "grilos" a procurarem execuçōes fictícias para se apoderarem do terras que continuavam de propriedade da Nação.

O Govêrno Federal procurou remediar êsse mal, removendo-lhe a causa, pelo saneamento da regiāo, obra patriótica e grandiosa, em plena execuçāo, mas lenta na sua marcha em relaçäo à extensão da zona.

O saneamento, todavia, não resolvia por si só o problema, mesmo para as terras saneadas, continuando êle a pedir solução pela remoção das outras causas. Sob certos aspectos, o saneamento, paradoxalmente, agravou a situação, porque, se valorizava as terras saneadas, deizava-as nas mãos dos que năo podiam ou não queriam aproveitá-las, continuando inacessíveis aos que, desojando fazê-lo, não o podiam, por não disporem dos recurso necessários pará as adquirir. 
O remédio estaria na colonização des terras, promovida pelo próprio Govêrno Federal, por meio da criaçēo de Núcleos Coloniais, para a localizaçāo de pequenos agricultores. Mas, para que êsse programa pudesse ser cumprido, fazia-se maister, antes de tudo, coma medida preliminar, resolver a questão relativa à propriedade das terras, que teriam de ser incluídas no plano de colonização. Proprietária de grande parte delas, era natural que por ai começasse. Como, porém, se thes perdera a posse, a benefício de ocupante* intrusos, apesar de the pertencerem por titulos inequivocos?

Regularmente, de acôrdo com a legislação comum do país, teria de recorrer ao Poder Judiciário, intentando as açōes adequadas aos casos, com as delongas da rotina processual. A ter de sujeitar-se a isso, melhor era desistir da obra planejada, pelo tempo que teria de perder na espera das decisões judiciárias passadas em julgado.

Inversäo do ônus da prova - O Dacreto-lei $n^{\circ} 893$, deu solução ao caso, estabelecendo um regime jurídico especial para as terras em vista, cujas lirhas gerais sāo as seguintes :

A ordem jurídica é invertida no que diz respeito ao ônus da prova. En vez da União invocar os seus títulos de proprietário, contra os que ocupana terras do Patrimônio da Nação, em cada caso, adotou o Decreto-lei n. ${ }^{\circ} 893$, como medida gera!, a obrigatoriedade, para todos os foreiros, arrendatários, possuidores, ocupantes e quantos se julguem corn direito a qualquer porção de terras na Fazenda Nacional de Santa Cruz e em outros imóveis da Uniáo situados na Baixada Fluminense, de exibitem os titulos em que funciam o seu direito, a comissöes especiais que, para êsse fím, serão nomeadas pelo Presidente da República (art. $2^{\circ}$ ), dentro do prazo de três meses márcado por editais publicados no Diário oficizal e em dois jornais de grande circulação (art. $20^{\circ}$, parágrấo único).

Essa inversão do ônus da prova, aparentemente arbitrária, é gutorizada pela norma constitucional contida no art. 123, última parte, da Carta, yus dá como limite ao uso dos direitos e garantias individuzís as necessidades da defesa do bem estar, da paz e da ordem coletiva; e, bem compreendida nos seus efeitos, é também de grande utilidade para os que são alcançados pela medida, eis que thes dá oportunidade para regularizarem definitivamente a sua posição em frente à Fazenda Nacional, pelo reconherimento por esta doø títulos legítimos sôbre terras alodiais ou regularmente aforadas quando fôr - caso, e facilidades concedidas acs ocupantes, mesmo sem título de qualcquer natureza, para a aquisição do domínio pleno das mesmas, desde que velas possuam benfeitorias as estiverem cultivando, por si e repularmente (art. 8.9).

A Comissäo Revisora de Títulos - - Para receber os titulos e julgat a sua legitimidade, foi designada a Primeira Comissão Especial Revisora da Titulos de Terras (P.C.E.R.T.T.), com sede nesta Capital o constituída de três membros: o consultor jurídico do Minnistério da Agricultura, autor destas linhas, o então Procurador da R€pública ro Estado do Rio de Janeiro, hoje 3. Procurado- da República na Capital Federal, Dr. Plínio de Freitas Travassos, e o Chefe da Seção de Engenharia da Divisão de Terres e Colonização, engenheiro civil Henrique Dietrich, era plena atividade desde o* princípios de 1939.

Ao receber a noticia de minha designação, declinei da honra que me era conferida, por me parecer que o Decreto-lej n. 893 continha disposíçōes des ¿duvidosa constiturionalidade, além de outras que, por excessivamente discrionárias, atritavam com @ minha mentalidade jurídica, forrnada de acôtdo com os princípios clássicos, muitas vêzes desatendidos pelo legislador. Mantida, 
porém, a designação, não tardei a capacitar-me, ao aplicar a lei, nos caso submetidos no meu estudo, da benemerência dos dispositivos que so me afiguravan, à primeira vista, desnecessàriamente atentatórios dos direitos individuais.

Exame e legitimidade dos títulos - Vejamos como se explica o paradexo, começando pelo que se refere aos portadores de títulos presumivelmente legítimos, de acôrdo com as normas do direito comum, por devidamente transcritos no Registro de Imóveis.

Referiam-se êsses títulos a terras alodiais e a terras do domínio direto da União regularmente aforadas.

Essa diferença não podia ser estabelecida mediante a simples existència do título de aquisição de propriedade, inúmeras vêzes declarada plena quando, na realidade, compreendia apenas o domínio útil e, em alguns casos, por mais estranho que pareça, figurando no título como de terras foreiras, mas depois verificado pela Comissão ser de terras alodiais.

A incerteza do título, quanto à natureza da propriedade nêle indicada, constituía para seus titulares motivo de apreensão e para a propriedade motivo de desvalorização. Sendo imprescritíveis os beng da União, podia esta fazer valer os seus direitos em qualquer tempo, e deixava duvidosa a situação mesmo paro os que houvessem adquirido terras regularmente desmembradas do patrimônio nacional pelos processos para isso usados : - a concessão de sesmarias, a doação, a venda direta e a remissão de foros.

Terras compzeendidas no perímetro da antiga Imperial Fazenda de Santa Cruz que não houvessem passado à propriedado privada por um daqueles processos, continuavam na propriedade da União. Como, porém, chegar-se à discriminação exata uma do outra, dentro da ordem estabelecida de acôrdo com as normas da legislação comum?

No Decreto-lei n.o 893 , o legislador encontrou o remédio adequado para o mal.

A P.C.E.R.T.T. terão de ser apresentados todos os títulos, qualquer que seja a sua procedência, para que examine origem da propriedade, lançando māo de meios de investigação dificilmente ao alcance da grande maioria de proprietários.

Exaustivo e ciclćpico tem sido o trabalho da Comissão nesse sentido, mas o resultado justificou-o. Com o auxílio da Seção de Engenharia da Divisão de Terras e Colonização, foi possível identificar e localizar as sesmarias concedidas dentro do perímetro da antiga Imperial Fazenda de Santa Cruz; e dentro dos respectivos perímetros terras a que se referem os títulos apresentados para julgamento da Comissão. O trabalho relativo à identificação das sesmarias está quase ultimado, pouco faltando para completar o mosaico representado por elas na planta da Fazenda. O relativo à identificação das terras desmembradas das sesmarias para constituírem propriedades independentes, está em processo, já tendo a Comissão liberado inúmeros títulos, com grande vantagem para os respectivos proprietários, agora a coberto de quaisquer surprêsas futuras sôbre a natureza da propriedade, vantagem que lhes foi possível ser assegurada pela medida, aparentemente vexatória, a que foram obrigatòriamente submetidos pelo Decreto-lei n. ${ }^{\circ} 893$, sob êsse ponto de vista, mais benéfico para o proprietário particular do que para a União.

Se o desmembramento do patrimônio nacional se dera por doação, venda direta ou remissão de foros, reinando idêntica confusão nos títulos de propriedade de terras próprias com aqueles origens, o interêsse dos titulares está 
em qua desapareça a confusão, e o meio de o conseguir mais rápido e mencs dispendioso é o de submeter os títulos à Comissão pera que esta faça a discriminação, focalizando, primeiro, às áreas doadas, vendidas ou remidas e dentro delas as terras posteriormente fracionadas.

Quando a propriedade particular recai apenas sôbre o domínio útil, a discriminação texá de ser feita entre as terras que continuam regularmente afcradas, das que cairam en comisso. Na primeira hipótese, a apresentação da carta de aforamento e a prova do pagamento dos foros, ou documentos qua os substituam, resolvem a situação para o foreiro. $\mathrm{Na}$ segunda bipótese, o aforamento é declarado extinto, por ‘̂́rça do disposto no art. $50^{\circ}$ e se'z parágrafo único,

Cono o regime de aforamentos nāo tem dado bons resultados, uma vez caídos em comisso não poderão ser yenovados pela purgação da mora, paxsando as terras para o domínio pleno da Uaião, pela incorporação do domínio útil 20 direto, indenizando-se o foreiro pelo valor das benfeitorias.

As terras serão aproveitedas pelo Govêrno de acôrdo com o plano dia colonização, mas caso não corttrariem a execução dêsse plano, ao foreiro ficia ressalvado o direito de adquirir a doraínio direto, se a comisso é recente, pagos os forcs em atraso (art. $6^{\circ}$ ), ou o domínio pleno, se o comisso $\dot{\theta}$ antigo, deduzido do preço o valor das benfeitorias que tiver realizado (artigo 6.', parágrafo único).

Cabe ainda à União imitir-se na posse de terras regularmente aforadas, no caso do foreiro transferir o domínio útil, por venda ou cessão, ̀̀ revelia do senhorio direto. $O$ direito de opção, que the é assegurado pelo art. 685 do Código Civil, é ampliado pelo art. $70^{\circ}$ do Decreto-lei $n^{\circ} 893$, para que a Uniäo se invista da posse das terras, independentemente de qualquer formalidade, além do pagamento prévio do preço da aquisição. Pode, entretanto, a União não querer valer-se da faculdade. Omisso o decreto-lei, a Comissão teve de preencher a lacuna, nos inúmeros casos que se the deparavam para julgar, decidindo, de acôrdo com o espírito da lei, por analogia de situaçöes, que ao adquirente ficava assegurada a preferência para a compra de terras, acrescido ao preço da venda a imporância relativa ao laudêmio, que deixara: de ser pago, com as juros de mors. Esse modo de decidir, baseado na equidade, se impunha, por nāo ser possível, no regime do Decreto-lei no 893 , ש sobrevivência de aforamentos em situação irregular. A Uniāo, podendo readquirir o domínio útil das terras a propriedade das benfeitorias nelas existentes, pelo pagamento do preço da venda ou cessäo, não se aproveita da faculdade, em beneficio do adquirente, ao qual permite näo sòmente continuar na posses das terras como ainda guardá-las em plena propriedade, pagando o valor cor respondente do domínio direto. Se se tiver em vista que êsse valor é calculado em base muito inferior ao obtido pelss terras alodiais da: zona, é incontestável a vantagem concedida ao que se apresentava perante a União como simples ocupante das terras.

Nem tôdas as terras da Fazenda Nacional de Santa Cruz, que continuam no patrimônic da União, folam, porém, objeto de aforamentos 4 Grande parte delas foraun simplesmente arrendadas ou ainda se encontram baldias sendo que, destas últimas, muitas foran apossadas clandestinamente por intrusos.

Benfeitorias. Preferencia para aquinicão - Para tais ocupantes, arrenslatários ou näo, o Decreto-lei n. ${ }^{\circ} 893$ criou uma situação verdadeiramente providencial, oo prescrever no art. $8 .^{\circ}$ que :

"Ao dono de benfeitorias que, emhora sem título legitimo de propriedade, estiver cultivando, por si regularmente, terras com- 
preendidas na definição do art. $20^{\circ}$, fica assegurada preferência para a sua oquisiçäo, e se nẽo quiser gozar dessa preferência terá direito à indenização dessas benfeitorias".

Quaisquer demasias do decreto-lei são largamente compensadas por aquela franquia, de uma liberalidade impossivel de superar. E' uma bandeira do misericórdia que cobre tôdas as transgressöes contra a Fazenda Nacional, sob a condição única do transgressor estar aproveitando as terras, em cultura regular. Para os que satisfizerem essa condição, o decreto-lei não distingue o intruso do arrendatário, concedendo a ambos a mesma oportunidade de se tornarem legítimos proprietários das terras ocupadas.

A liberalidade veio dar solução a situaçōes que se revelaram insolúveis dentro do regime legal a que estão submetidas as terras do domínio da União, de acôrdo com o qual a menor irregularidade verificada na instrução dos pedidos de aforamento era motivo para indeferimento, o mesmo ocorrendo no processamento dos pedidos de transferência do domínio útil, sempre demorados, demora que os interessados contornavam fazendo as vendas ou cessōes por meio de procurações com poderes irrevogáveis em causa própria, instrumento inoperante nas alienaçōes de imóveis, mas usado com tanta freqüência que entrou nas legislações fiscais de alguns Estados e do Distrito Federal como suficiente para a cobrança do impôsto de transferência da propriedade de imóveis.

Transitavam no Serviço do Patrimônio da União centenas de processas com muitos anos de andamento, durante o qual se operavam sucessivas transferências, irregularmente, dificultando ou tornando impossivel qualquer solução, so observado o regime legal.

A Comissão teve oportunidade de examinar processos, que the foram encaminhados pelo S.P.U. em apoio de informaçóes prestadas, a propósito de requerimentos de ocupantes de terras da Fazenda Nacional de Santa Cruz, iniciados nos primeiros anos da República e ainda nāo solucionados, como o de dona Lídia Rebofini, que datava de 1892, resolvido, afinal, pela Comissão 50 anos depois!

O art $8^{\circ}$ do Decreto-lei n. $^{\circ} 893$ tornou possível a solução pronta para todos êsses casos, com satisfação plena tanto do interêsse da parte quanto do da União, que é o de ver convenientemente aproveitadas por agricultores as terras do domínio público não destinadas a fins específicos. Não sendo a União negociante de terrenos e tendo alguns ocupados, embora indevidamente, por pessoas que se mostram dispostas a cultivá-los, melhor é que, em vez de criar embaraços à legalização dessas ocupações, a facilite, permitindo que o ocupante consolide s sua situação, pela aquisição das terras.

Se a ocupação indevida foi possível é porque as terras estavam abandoandas pelos representantes da União encarregados de sua guarda, mantendo-se improdutivas e inúteis. Mas a função da terra é produzir, sendo justo que, ao que a reintegrou nessa função, seja concedido ficar seu proprietário, adquirindo-as da União, se manifestar desejo nesse sentido.

A milhares de ocupantes nessas condiçōes reconheceu a Comissão direito à preferência legal, mediante a verificaçāo sumária da efetividade da ocupação e da existência das benfeitorias alegadas.

A frase atribuida ao papa Zacarias, ao concordar com a destituição do áltimo merovíngio a favor de Pepino, o Breve, filho de Carlos Martel, de que "valia mais que fôsse rei aquêle que na realidade exercia o poder real", foì aplicada, no seu espírito, pelo legislador aos ocupantes de terras do Domínio da União, que as traziam cultivadas, mais valendo que ficassem donos delas on que já agiamn como se o fôssem, na sua finalidade especifican. 
Sem pretender concluir que o fato seja devido à liberalidade legal, a ela pode ser atribuída relativamente parte na valorização que, nos últimos tempos, se cperou nas terras vizinhas à Capital Federal, situadas nos lugares mais depreciados, avaliadas agora en milhares de cruzeiros por alqueirs. quando o eram, dantes, por escessas dezenas de mil-réis nos inventários em: que figuravam como bens de espólios.

Nesse particular, o Decreto-lei n. 893 manteve a tradição brasileirł: sôbre a aquỉsiçâo da propriedede territorial pela ocupação, que sempre pre. cedia à expedição das cartas de sesmarias aos que as requeriam alegando já estarem na posse das terras e as traziam aproveitadas em lavouras, para o que dispunham de escravos e haveres.

A extensão territorial do pais justificava a adoção desse processo de povcasmento, pelo que foi tolerado depoís da Independência e ainda hoje é empregado com utilidade nos Estados de grandes territórios, embora as respectivas leis de terras não reconheçam senão a venda como meio legal para a aquisição de terras devolutas, requeridas aos governos locais sempre depois de apossam das e exploradas, o que é perfeitamente compreensivel. Os seringaís da Amazônie, na sua grande maioria, mesmo no período áureo da borracha, constituiam simples posses e o que lhes dava valor não era a extensão das terras, mas o número de estradas de seringueiras que nelas foram abertas, isto é, c esfôrço do homem em prepará-las para a fabricação do produto. A3 terras, por si mesmas, nada valiam, e foram abardonadas, inclusive pelos que tinharma títulos legítimos, quando crise de desvalorização $d_{a}$ borracha de origema eilvestre atingiu os eringais da regiäo.

O legislador, no Decreto-lei n. ${ }^{\circ}$ 893, aplicou às terras do domínio ds: União situadas na Fazenda Nacional de Santa Cruz o critério tradicional brasileiro, garantindo ao ocupante que as traz aproveitadas o direito de adquirilas, ainda que não possa apresentar śtulos de qualquer natureza.

Coerentemente com êsse critério, nenhum direito reconhece aos que as trazem abandonadas, se não puderem apresentar titulos de propriedade * coberto de chualquer vício de origem.

Cartas de arrematação - Estão nesse caso as cartas de arremataçäo expedidas em executivos fiscais para a cobrança do impôsto territorial, uma das maneiras empregadas para a apropriação, com aparência de legalidadé. de terras do dominio público, inspirada nas execuçōes movidas por falta do pagamento daquele impôsto contra os proprietários das terras por êles abandonadas. Feita a inscrição fictícia das terras nas coletorias estaduais por simples declareçāo verbal do interessado, para efeito do lançamento do impôsto propositalmente, no exercício próximo, movido o executivo fiscal contro - suposto proprietário das terrag, desconhecido na regiäo e dado como em. lugar incerto pelo oficial do justiça encarregado da diligência, corria o processoà revelia, sendo arremstadas as terras penhoradas, por preço irrisório, pelo que preparava o golpe.

Passada a carta de arrematação, seu portador estava armado de um título, que só poderia ser destruido pela Uniãc em açäo judicial própria, e como esta nunca era proposta, consumava-se o grilo sem qualquer dificuldade.

O Decreto-lei $n_{0}^{\circ} 893$ deu atribuições à Comissão para julger a legitimidade de tais títulos, pela investigaçảo de suas origens, negendo-a se inquinados daquele vício. Proferida a decisão, fican invertidos os papéis - ema rez de caber à União o ônus de pedir em juízo a anulação do título de acôrclo com a legislação comum, ao titular é que caberá a iniciativa, não para restaurar o th̆tulo, senão apenas para mever contra a União ação de perdas a denos, no curso da qual terá de fazer a prova de que o executivo fiscal so basesve em impôsto territorial devido pelo executado, legítimo proprietário 
das terras arrematadas, isso porque, contra as decisôes da Comissão, não é admivável nem ação possesab́ria, nem açāo de reivindicaçöes, nos têrmos do art 18, que prescreve:

"Não poderá ser tomada contra a União qualquer medida judicial que perturbe a livre disposição das terras a que se refere esta lei".

A Comissão, no curso de seus trabalhos, teve ocasião de negar a legitit midade a várias cartas de arrematação expedidas pelo Juízo dos Feitos da Fazenda Pública do Estado do Rio de Janeiro, restituindo ao patrimônio da Uniāo vastas áreas em poder de particulares por aquêle meio.

Se o titular da carta de arrematação, apesar do vício original desta, prova que tras as terras em cultura por si e regularmente, a êsse mesmo é concedido o benefício do art. $8 .^{\circ}$, na qualidade de ocupante, com benfeitorias nas terras, se anteriores à vigência do decreto-lei.

Também são inquinadas de nulidade de pleno direito as alienaçōes, arrematações ou adjudicações de terras sujeitas ao regime especial, sem prévia audiência do Ministério da Agricultura, nem podem ser transcritos os respectiros títulos sem que seja feita a prove de que as terras a que os mesmos se referem foram liberadas pela Comissão, sob pena de multa de $C_{r} \$ 5.000,00$ para o oficial que efetuar a transcrição, e demissão no caso de reincidência (art. 22 e $8 .^{\circ}$ ).

Esses rigores sāo indispensáveis não sòmente para a defesa dos interêsses da União, senão também para a maior segurança dos proprietários das terras, nas transações que sôbre elas realizarem, pelo afastamento completo da insegurança que acompanhava os títulos de propriedade anteriores e não revistos pela mesma Comissão.

Se as terras interessarem ao plano de colonização a cargo do Ministério da Agricultura, o que êste declarará no prazo de 30 dias (art. 30 e seu parágrafo único), indenizará o Govêrno Federal ao ocupante as benfeitorias que nelas possuir.

O legislador teve o cuidado de cercar de garantias o ocupante que mantém as terras em cultivo regular, assegurando-lhe a preferência para a sua aquisiçāo, com facilidades e vantagens sôbre estranhos, coso sejam julgadas desnecessárias ao plano de colonização, ou indenizando-o do valor das benfeitorias existentes, na hipótese contrária.

A Comissão, sempre que encontra terras devidamente aproveitadas pelo seu ocupante, partindo do princípio de que a finalidade do decreto-lei já está atingida no caso, decide pela preferência para a sua aquisição. Na rea lidade, seria contraditório que o Govêrno sujeitasse ao plano de colonização, cujo fím é facilitar o aproveitamento das terras do domínio da Uniāo que se conservam improdutivas, as que já se apresentam cultivadas por seus atuais ocupantes, retirando-as da posse dêstes para as entregar, mais tarde, a terceiros, em lotes coloniais, quando jé houvessem desaparecido as culturas anteriormente existentes, pelo abandono em que teriam necessáriamente de ficar durante o processo de loteamento, e subseqüente distribuição dos lotes zos colonos a quem fôssem concedidos, o que se faz sempre com grandie demora.

Contra êsse critério, a Divisão de Terras e Colonização levantou o argumento de que a sua adoção criaria nos Núcleos Coloniais verdadeiros quistos constituídos pelas terres, cuja propriedade não pertencesse a colonos. $O$ inconveniente poderá ser e tem sido abrandado por meio de condiçōes impostas na escritura de aquisição e qualquer que êle seja será sempre menor do que o 
ecima epontado - desfazer o que já está feito dentro da finalidade da laj para observar cegamente, nos seus rínimos detalhes, o regime de aproveita mento por meio de Núcleos Coloniais, erhbor

Felizmente, poucos foram os casos em que a Comissão tov de aplica - critério, nenhum mal dá advỉndo para o plano de colonização en execução

O prazo de três meses marcado pelo art. $2^{\circ}$, parágrafo único, para : exibiçāo dos títulos, foi reaberto duats vêzes pelo Govêrno, a fim de que o interessados pudessem comparecer perante a Comissäo, e evitar a incidênci no art. $4 .^{\circ}$ e sẹ parágrafo único, pelơs quais a não apresentação dos títıl’: ou seu não reconhecimento como legítimos importará ipso tacto no investi zaento da União na posse das terras, não eakendo ação judicial para reivin dicação de domínio.

Os que deixaram de cumprir a exigência legal, nos três prazos quo par: isso lhes foram marcados, parece terem sido pcucos e só poderão queizar-se di si mesmos.

A Comissão abrandou a aplicação da noma t̀ terras legalmento des membradas do patrimônio nacional, recebendo, em qualquer tempo, par: exame, os títulos que the são apresentados com a decleração de que se refe rem a terras próprias, por the parecer que a cominação legal, quanto ao rigo do prazo, não deve atingir senão as que continuam do Domínio da União, cujo títulos nāo foram apresentados, ou, epresentados, não foram reconhecido. como legítimos.

Encerrados que sejam, todevia, as trabelhos da Comissão sem que o interessados hajam exibido os seus títulos de propriedade plene para o fin da lei, arriscam-se êles a ficar impedidos, pràticamente, de negociar com terras, pôsto que năo poderão ser transcritos on títulos de trarsferência di propriedade, por fốrça do disposto $n_{2}$ art. 22 e seus parágrafos.

Esses displicentes, menos do que quaisçuer outros, poderão queixør-s: dos rigores da lei.

Posteriormente à vigência do Decreto-lei n. 893 , o regime prescrito ar mesmo foi mandado estender, pelo Decreto $n^{\circ} 5.510$, de 12-1.1940, con a retificação publicada no Diário Oficial de 3-2-1941), a outros imóveis de domínio da Unão, indicados nos cinco incisos do art. $1 .^{\circ}$, e, ùltimamente pelo Decreto-lei $n^{0}{ }^{0} \mathbf{7 . 0 7 3}$, de 23-1 1944 , aos terrenos situados em Jacare paguá, Distrito Federal, utilizadog pela Coordenação da Mobilizaçäo Fconô mica, de que trata o Decreto-lei $\mathrm{n}^{\circ} \mathbf{5 . 8 7 7}$, de 4-10-1943.

Do início de seus trabslhos, orn 21 de janziro de 1939, a 31 de dexeriba de 1944, a P.C.E.R.T.T. recebev em seu protocolo 5.840 requerimeato - proferiu 2.325 decisōes definitivas e 4.822 despachos interlocutórios, ten realizado 514 sessões, a razão de duas por semana, nas quais examinou fara cirna de vinte mil títulcs e documentos, likerando os que foram julgado: legítimos.

On trabalho: continuams êste ano guardando o mesmo ritmo.

Vantagers do Decreto-lei n. ${ }^{\circ}$ 893. Conclusöes - As vantagens do De creto-lei n. ${ }^{\circ} 893$, de 26-11-1938, pollem ser assim resumidas :

a) permitir à União conhecer exatamente quais são as terran que forain regularmente; desmembradas do património nacional, passando para a pro priedade privada, o maios legais por que se efetuaram os desmembramentos: cartas de sesmatias, doaçöes, vendas diretas e remissöes de foros, tendo sirle sitaladas na plants da antiga Imperifl Fazenda de Santa Cruz tôdas as sesmarias concedidas dentro do perimetro desta; 
b) por sua vez, os particuleres adquirentes de terras desmembradas das sesmarias ou das alienadas por outra forma, ficaram com a sua propriodado definitivamente reconhecida pela Uniāo, cessando a incertexa até aí reizante sôbre a natureza da mesma propriedade;

c) das terras aforadas, foi feita a discriminação entre as que continuarão. no regime enfitêutico das que, por terem caído em comisso os respectivos aforamentos ou por ter o domínio útil sido tranaferido sem audiência prévia da União, saíram daquele regime, independentemente de qualquer medida judiciária;

d) aos ocupantes de terras, mesmo sem qualquer título, que sāo donos das benfeitorias existentes nas mesmas as traxem cultivadas regularmonte, foi facilitada a aquisição, mediante a simples prova da ocupação e da existência das benfeitorias, anteriores à vigência do decreto-lei, dando a mais plástica das soluções, por sua simplicidade e senso da realidade, tendo em vista os interêsses em jôgo, tanto particulares como coletivos, a um problema de administração que parecia insolúvel dentro das normas de legislação comum;

e) ao encerrar seus trabalhos, a P.C.E.R.T.T. terá deirado completamente esclarecida a situação de tôdas as terras situadas dentro do perímetro da antiga Imperial Fazenda de Santa Cruz, alodiais, foreiras e do domínio pleno da União, cessando o estedo de confusāo até então reinante, numa obra silenciosa, mas $100 \%$ eficiente, com satisfação plena de todos os interêssee am jôgo, e uma despesa, para o Tesouro Nacional, que não atingirá $\mathrm{Cr}$ $200.000,00$. 